\title{
Dyspnoea at rest and at the end of different exercises in patients with near-fatal asthma
}

\author{
E. Barreiro*, J. Gea*\#, C. Sanjuás\#, R. Marcos*, J. Broquetas\#, J. Milic-Emili"
}

Dyspnoea at rest and at the end of different exercises in patients with near-fatal asthma. E. Barreiro, J. Gea, C. Sanjuás, R. Marcos, J. Broquetas, J. Milic-Emili. (C) ERS Journals Ltd 2004.

ABSTRACT: Blunted perception of dyspnoea under resistive loading has been observed in patients with a history of near-fatal asthma (NFA). The perception of dyspnoea at rest and at the end point of various exercises was assessed in such patients.

Respiratory function and exercise capacity (6-min walking distance, incremental cycloergometry and inspiratory threshold loading) were assessed in seven NFA and eight non-NFA patients. Dyspnoea (Borg scale) was measured at rest and at the end point of the various exercises.

Dyspnoea at rest was significantly lower in NFA patients. Although exercise tolerance was similarly reduced in both the NFA and non-NFA groups, dyspnoea at peak cycle exercise was significantly lower in the former $(2.6 \pm 2$ versus $6.1 \pm 3.8$ (Borg scale; mean \pm SD)), who mainly (86\%) stopped because of leg discomfort. A similar trend was observed in the 6-min walking distance and inspiratory threshold loading tests. Dyspnoea at peak exercise was the best indicator of the NFA condition, with a sensitivity of $100 \%$ and specificity of $63 \%$ for a Borg scale score of $\leqslant 6$.

Perception of dyspnoea is blunted in near-fatal asthma patients at both rest and the end point of various forms of exercise. Dyspnoea at peak exercise is the best indicator of the near-fatal asthma condition.

Eur Respir J 2004; 24: 219-225.
*Muscle Research Unit, Municipal Medical Research Institute, Pompeu Fabra University, and ${ }^{\#}$ Respiratory Medicine Dept, Hospital del Mar, Universitat Autònoma de Barcelona, Barcelona, Spain. "Meakins-Christie Laboratories, McGill University, Montreal, Canada.

Correspondence: J. Gea, Respiratory Medicine Dept, IMIM - Hospital del Mar, C/ Doctor Aiguader, 80, E-08003 Barcelona, Spain.

Fax: 34932213237

E-mail: jgea@imim.es

Keywords: Dyspnoea, exercise, near-fatal asthma, respiratory loading

Received: June 302003

Accepted after revision: March 12004

This study was supported by grants BHM4CT-96-1471 from the European Union (Brussels, Belgium), 97/1197 E from the Spanish Health Investigation Agency (Madrid, Spain) and 131056 from the Medical Research in Respiratory Medicine Association (Barcelona, Spain).
Asthma is one of the most common public health problems, and has shown a progressive increase in morbidity and mortality [1-4]. Reports on asthma deaths have put forward the hypothesis that a lack of recognition of the severity of the disease by patients may have contributed to the increase in mortality rates $[2,3]$. Severe asthma covers a broad range of different clinical patterns, from patients who have experienced respiratory arrest to subjects with severe airflow obstruction, or undergoing long-term treatment with oral steroids.

A life-threatening asthma attack remains a major problem in the clinical management of severe asthma patients, and occurs in both fatal asthma and near-fatal asthma (NFA) [5-7]. NFA appears to be associated with more emergency department visits, hospitalisations, deaths and lung function impairment [8, 9]. Moreover, KIKUCHI et al. [10] showed that those patients with a history of NFA exhibit blunted perception of dyspnoea in response to inspiration against resistance and to hypoxia.

It was hypothesised that those patients who have experienced an NFA attack should report a lower perception of dyspnoea under other conditions, specifically those related to physical exercise, compared to severe but non-NFA asthma patients. Accordingly, the main aim of the present study was to assess the perception of dyspnoea, at both rest and the end point of various standard exercise tests in these two populations.

For editorial comments see page 197.
Methods

\section{Subjects}

Seven consecutive patients who had had chronic asthma along with a history of at least one NFA attack were included. NFA was defined as respiratory arrest and/or a carbon dioxide tension $\left(\mathrm{Pa}_{1}, \mathrm{CO}_{2}\right)$ of $\geqslant 6.7 \mathrm{kPa}(\geqslant 50 \mathrm{mmHg})$. Eight consecutive patients with chronic severe asthma without a history of NFA were also included as the control group. All individuals from these two groups were simultaneously participating in the European Network For Understanding Mechanisms of Severe Asthma (ENFUMOSA) study, designed to investigate the mechanisms involved in severe asthma. Diagnosis of chronic severe asthma was made in accordance with both the international consensus report on the diagnosis and treatment of asthma [11] and the statement formulated by the expert panel of the ENFUMOSA project. As is commonly accepted, the definition of severe asthma was based on not only functional impairment but also both clinical findings and treatment [11].

\section{Inclusion criteria}

All 15 patients in the two groups had a history of intermittent or persistent symptoms such as wheezing, breathlessness, chest tightness and coughing, and documented 
reversible airway obstruction within the 5 yrs previous to study entry. Patients from both groups had also been previously hospitalised due to asthma.

NFA patients fulfilled the previous criteria and also had a history of at least one NFA attack within the 5 yrs previous to study entry. Control group patients had had chronic severe asthma for $\geqslant 1 \mathrm{yr}$, had required care by an asthma specialist, had received high-dose inhaled corticosteroids and longacting $\beta$-agonists or theophylline for $\geqslant 1 \mathrm{yr}$, and had received at least either two short courses or a 3-month course of oral steroids within the year previous to study entry.

Both age and sex distributions were similar in both groups. Given the severity of their condition, all patients were asked not to refrain from their usual therapy during the study. Smokers were excluded. The protocol was approved by the Ethics Committee of the Municipal Medical Research Institute (Barcelona, Spain) and each volunteer signed the informed consent form.

\section{Procedures}

Pulmonary function tests. Forced spirometry was carried out using a pneumotachograph (Datospir 92; Sibel, Barcelona, Spain) and standard procedures [12]. In order to test whether the obstruction was reversible, forced expiratory volume in one second (FEV1) was measured before and $15 \mathrm{~min}$ after four inhalations of $100 \mu \mathrm{g}$ salbutamol, administered through a large-volume spacer. Further assessment of hyperresponsiveness was rejected by the Ethical Committee due to both the severity of the disease and the previous history of NFA in one of the groups. Static lung volumes and specific airway resistance (sRaw) were determined using body plethysmography (Masterlab; Jaeger, Würzburg, Germany). Inspiratory capacity (IC) was measured during a slow maximal inspiratory manoeuvre from the resting end-expiratory level. At least two measurements were made in each case, and the highest value selected. The carbon monoxide diffusing capacity of the lung ( $D \mathrm{~L}, \mathrm{CO})$ was also measured (Masterlab). Data from RocA and co-workers [13-15] were used as the predicted values. Arterial blood gas levels were determined using a standard gas analyser (ABL 330; Radiometer, Copenhagen, Denmark).

Respiratory and peripheral muscle function. Inspiratory muscle strength was assessed through determination of maximum inspiratory mouth pressure (MIP) (Sibelmed-163; Sibel) during an occluded maneouvre from residual volume. At least three manoeuvres were performed in each case, and the highest value selected. Reference values from MORALES et al. [16] were used. Peripheral muscle function was assessed through the handgrip manoeuvre, performed by the nondominant hand, using a Collins dynamometer (Herrera, Barcelona, Spain). At least three manoeuvres were performed in each case, and the highest value selected. The predicted values of MATHIOWETZ et al. [17] were used.

Dyspnoea. Before the study, patients were familiarised with the Borg scale [18], and its end points were anchored in such a manner that zero expressed the absence of dyspnoea and 10 "the most severe level of dyspnoea you could imagine or have ever undergone". By pointing to this Borg scale, patients rated their perceived dyspnoea at rest and at the end point of the various exercises. The intra-individual variation in dyspnoea score among different rest points was assessed. In addition, in a parallel study, the intra-individual variability in dyspnoea score at rest and peak exercise was assessed using data from two additional cycloergometric tests performed on different days.

General exercise capacity. General exercise capacity was assessed using both the standard 6-min walking distance (6MWD) test [19] and a progressive incremental exercise test performed on a cycloergometer (Crescent 864; Monark, Varberg, Sweden). The predicted values used for the 6MWD were those of ENRIGHT and SHERRILL [20]. The cycloergometric test consisted of a 3-min warm-up period at $25 \mathrm{~W}$, followed by $25-\mathrm{W}$ increments at 2-min intervals while the subject was pedalling at a constant frequency of 60 revolutions per minute (rpm). Breathing pattern, electrocardiogram and transcutaneous arterial oxygen saturation $\left(\mathrm{Sa}_{\mathrm{a}} \mathrm{O}_{2}\right)$ (3700 Biox; Ohmeda, Chicago, IL, USA) were continuously recorded. The exercise was stopped when at least three of the following criteria were reached: 1) a plateau of oxygen uptake $\left(V^{\prime} \mathrm{O}_{2}, \max \right)$ despite increasing workload; 2) a cardiac frequency within $5 \%$ of the maximal predicted value; 3 ) a gas exchange respiratory ratio of $>1.1$; and 4 ) inability to maintain a pedalling frequency at $60 \mathrm{rpm}$. At the end point of the exercise, patients were asked to indicate the level of dyspnoea and the main cause for interrupting the test (dyspnoea and/or leg discomfort). Maximum mechanical power output and $V^{\prime} \mathrm{O}_{2}$, max (Oxycon 3.2; Jaeger) were determined, and the predicted values of JONES et al. [21] were used.

Exercise capacity of respiratory muscles. The exercise capacity of the respiratory muscles was evaluated using a modified version of the test of MARTYN et al. [22], using an inspiratory threshold valve. The test consisted of 5-10 min of unloaded breathing, followed by $10-\mathrm{cmH}_{2} \mathrm{O}$ increments of inspiratory threshold loading (ITL) at 2-min intervals. Airway pressure was recorded throughout the test, which was stopped when the patient was incapable of opening the inspiratory valve during three consecutive inspiratory efforts. The pressure generated against the highest tolerated load for $\geqslant 60 \mathrm{~s}$ was defined as the maximal sustainable inspiratory pressure. Reference values were calculated from the data of FIz et al. [23].

\section{Study protocol}

Day 1. The initial evaluation included forced spirometry and measurement of airway responsiveness to salbutamol, thoracic gas volume, IC, sRaw, DL,CO, blood gas levels, MIP and handgrip force. After $30 \mathrm{~min}$ of rest, the level of dyspnoea was assessed. The patients then performed the ITL test, and IC and dyspnoea were determined at the end of this test, when task failure occurred.

Day 2. Forced spirometry was performed, and both IC and dyspnoea were again measured to determine the baseline level on day 2. Patients then performed the 6MWD test, and IC and dyspnoea were determined at the end point. Following a 30 min rest period, $\mathrm{Sa}, \mathrm{O}_{2}$ was verified, and both IC and dyspnoea were again determined. Patients then performed the cycloergometry test, IC and dyspnoea again being determined at the end point.

\section{Statistical analysis}

Data are presented as mean \pm SD. Wilcoxon and MannWhitney nonparametric tests were used for paired and unpaired comparisons, respectively. The percentage change from baseline was used, in each case, to describe the modifications at the end point of the various exercises. Spearman's 
coefficient was used to assess correlation. The intra-individual variability of the dyspnoea score at both rest and peak exercise was assessed through both variance analysis for repeated measurements and the variation coefficient (SD/ mean). Receiver operating curves were used to calculate the sensitivity and specificity of dyspnoea scores in identifying the NFA condition. Significance was established at a p-value of $\leqslant 0.05$.

\section{Results}

The main characteristics of the patients included in both groups are shown in table 1.

\section{Dyspnoea at rest and at the end point of the various exercises}

Borg dyspnoea scores at rest were significantly lower in the NFA group than in the non-NFA patients (table 1; fig. 1). In the latter group, Borg dyspnoea scores at rest correlated with baseline arterial oxygen tension $\left(\mathrm{Pa}, \mathrm{O}_{2}\right)$, whereas this was not the case in the NFA patients (fig. 2). The Borg dyspnoea score at rest did not correlate significantly with resting breathing pattern variables in either NFA or non-NFA patients.

At peak bicycle exercise, the Borg dyspnoea scores were significantly lower in the NFA group than in the non-NFA patients (fig. 1). A similar trend was observed in both the 6MWD and ITL tests ( $\mathrm{p}=0.12$ and 0.06 , respectively). At the end point of the ITL and 6MWD tests, levels of dyspnoea were significantly lower than at peak bicycle exercise in both groups $(\mathrm{p}<0.05)$.

Among the peak exercise variables shown in table 2, the Borg dyspnoea score at peak bicycle exercise correlated directly with resting sRaw, and negatively with the peak

Table 1.-Patient characteristics and resting respiratory and peripheral muscle function in near-fatal asthma (NFA) and non-NFA patients

\begin{tabular}{lcc}
\hline & NFA & Non-NFA \\
\hline Males/females n & $3 / 4$ & $3 / 5$ \\
Age yrs & $44 \pm 19$ & $49 \pm 11$ \\
BMI & $24 \pm 4$ & $27 \pm 4$ \\
FEV1\% pred & $62 \pm 19$ & $58 \pm 17$ \\
$\Delta$ FEV1 \% & $18 \pm 17$ & $17 \pm 12$ \\
FVC \% pred & $80 \pm 19$ & $75 \pm 17$ \\
FEV1/FVC \% & $60 \pm 8$ & $56 \pm 10$ \\
IC \% pred & $79 \pm 17$ & $77 \pm 22$ \\
FRC \% pred & $125 \pm 19$ & $127 \pm 25$ \\
RV \% pred & $178 \pm 49$ & $185 \pm 32$ \\
RV/TLC \% & $45 \pm 10$ & $48 \pm 6$ \\
sRaw \% pred & $271 \pm 126$ & $315 \pm 167$ \\
$P$ a, $\mathrm{O}_{2}$ mmHg & $93 \pm 8$ & $88 \pm 11$ \\
$P$ a,CO mmHg & $37.7 \pm 3.7$ \\
$D$ L,CO \% pred & $36.9 \pm 3.0$ & $91 \pm 14$ \\
MIP \% pred & $96 \pm 11$ & $88 \pm 26$ \\
HG \% pred & $76 \pm 35$ & $64 \pm 29$ \\
Dyspnoea Borg score & $63 \pm 17$ & $1.3 \pm 1.3 *$ \\
\hline Data are presented as mean & $0.1 \pm 0.4$ &
\end{tabular}

Data are presented as mean \pm SD. BMI: body mass index; FEV1: forced expiratory volume in one second; $\triangle$ FEV1: change in FEV1 following salbutamol (bronchodilator test); FVC: forced vital capacity; IC: inspiratory capacity; FRC: functional residual capacity; RV: residual volume; TLC: total lung capacity; $s$ Raw: specific airway resistance; $\mathrm{Pa}, \mathrm{O}_{2}$ : arterial oxygen tension; $\mathrm{Pa}, \mathrm{CO}_{2}$ : arterial carbon dioxide tension; $D$ L,CO: carbon monoxide diffusing capacity of the lung; MIP: maximal inspiratory pressure; HG: handgrip force; \% pred: percentage of the predicted value. *: $\mathrm{p}<0.05$ versus non-NFA. $(1 \mathrm{mmHg}=0.133 \mathrm{kPa})$. bicycle exercise $\mathrm{Sa}_{\mathrm{a}} \mathrm{O}_{2}$, in the non-NFA patients, but not in the NFA group (fig. 3). The Borg dyspnoea score at peak bicycle exercise did not show significant correlations with any of the other resting respiratory variables in either NFA or non-NFA patients.

The intra-individual variability of the dyspnoea scores at different baseline points (rest) was $0-5 \%$. Moreover, when

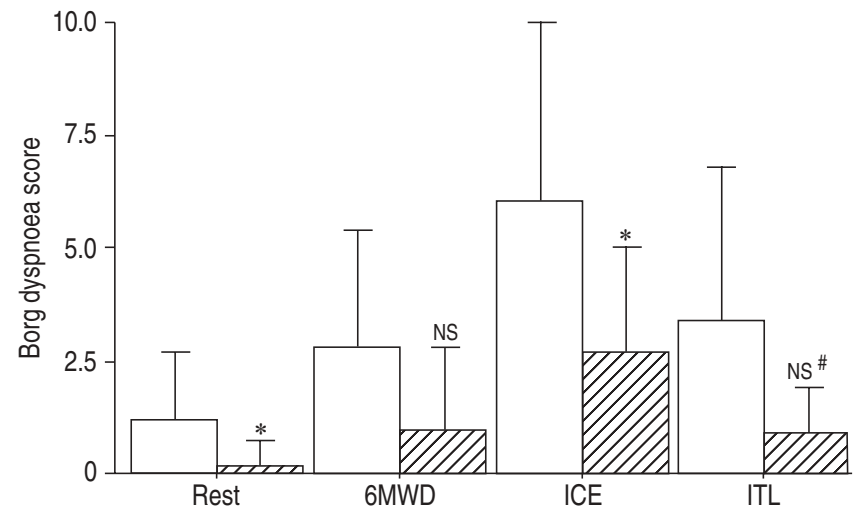

Fig. 1. - Borg dyspnoea scores reported by near-fatal asthma (NFA; $\mathbb{Z}$ ) and non-NFA $(\square)$ patients at rest and at the end point of various exercises. Data are presented as mean \pm SD. 6MWD: 6-min walking distance; ICE: incremental cycloergometry; ITL: inspiratory threshold loading. *: $\mathrm{p}<0.05$ versus non-NFA; ${ }^{\#}: \mathrm{p}=0.06$ versus non-NFA; NS: nonsignificant.
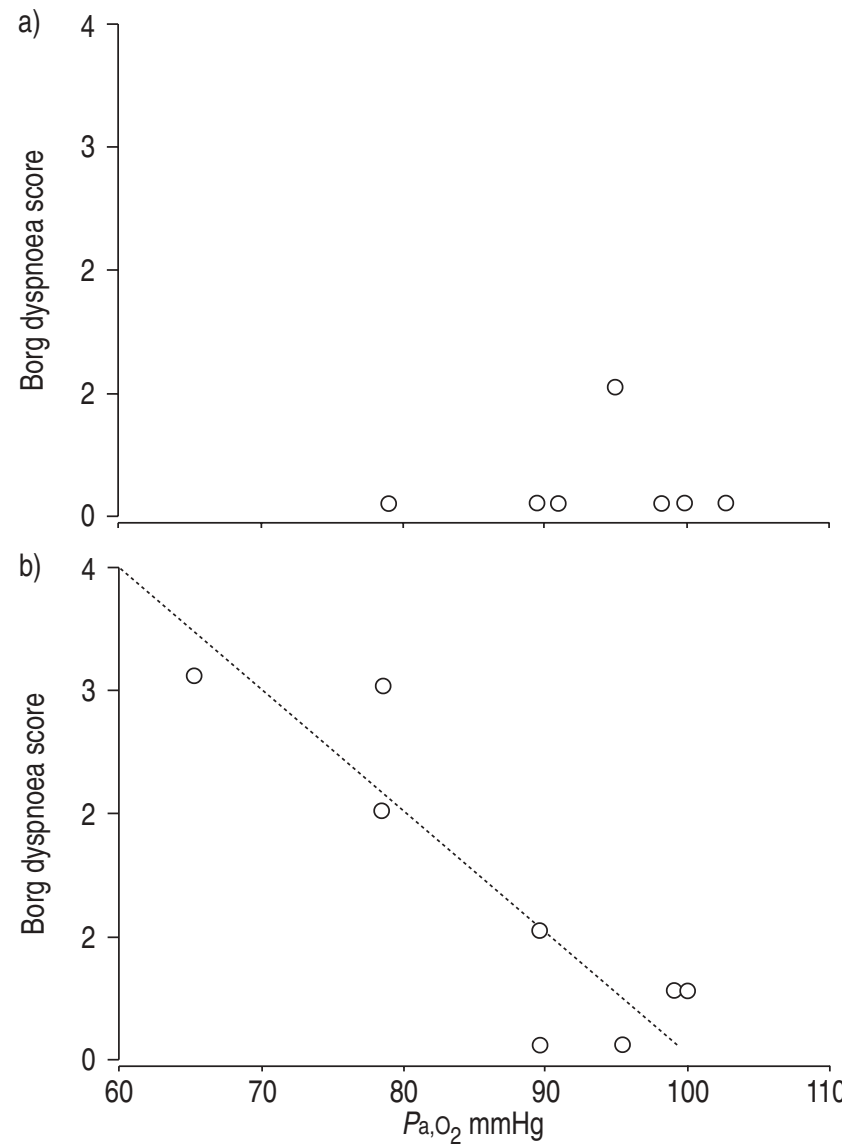

Fig. 2. - Relationship between resting arterial oxygen tension $\left(\mathrm{Pa}_{\mathrm{a}} \mathrm{O}_{2}\right)$ and Borg dyspnoea score in a) near-fatal asthma (NFA) and b) nonNFA $(r=-0.74, p<0.05)$ patients. $1 \mathrm{mmHg}=0.133 \mathrm{kPa}$. 
Table 2. - Exercise tolerance in near-fatal asthma (NFA) and non-NFA patients

\begin{tabular}{|c|c|c|}
\hline & NFA & Non-NFA \\
\hline Patients $n$ & 7 & 8 \\
\hline \multicolumn{3}{|l|}{ Incremental cycloergometry } \\
\hline$W \max \mathrm{W}$ & $129 \pm 56$ & $113 \pm 33$ \\
\hline$\%$ pred & $72 \pm 13$ & $78 \pm 20$ \\
\hline$V^{\prime} \mathrm{O}_{2}, \max \mathrm{mL} \cdot \min ^{-1}$ & $1256 \pm 620$ & $1421 \pm 442$ \\
\hline $\mathrm{mL} \cdot \mathrm{kg}$ body weight ${ }^{-1} \cdot \mathrm{min}^{-1}$ & $19 \pm 6$ & $20 \pm 5$ \\
\hline$\%$ pred & $73 \pm 14$ & $82 \pm 20$ \\
\hline$V \mathrm{~T} \mathrm{~L}$ & $1.4 \pm 0.7$ & $1.3 \pm 0.5$ \\
\hline$f \mathrm{R}$ breaths $\cdot \min ^{-1}$ & $35 \pm 4$ & $32 \pm 7$ \\
\hline$\Delta \mathrm{IC} \%$ & $-20 \pm 9 * *$ & $-10 \pm 9 *$ \\
\hline \multicolumn{3}{|l|}{ 6-min walking distance } \\
\hline Distance $\mathrm{m}$ & $468 \pm 111$ & $469 \pm 52$ \\
\hline$\%$ pred & $60 \pm 12$ & $72 \pm 20$ \\
\hline$\Delta \mathrm{IC} \%$ & $-6 \pm 9$ & $-5 \pm 16$ \\
\hline \multicolumn{3}{|l|}{ Inspiratory threshold loading } \\
\hline MSIP $\mathrm{cmH}_{2} \mathrm{O}$ & $67 \pm 28$ & $71 \pm 24$ \\
\hline$\%$ pred & $72 \pm 22$ & $86 \pm 18$ \\
\hline$\Delta \mathrm{IC} \%$ & $-10 \pm 20$ & $-6 \pm 8$ \\
\hline
\end{tabular}

Data are presented as mean \pm SD. $W$ max: maximal workload; $V^{\prime} \mathrm{O}_{2}$, max: maximal oxygen uptake; $V \mathrm{~T}$ : tidal volume at peak exercise; $f \mathrm{R}$ : respiratory frequency at peak exercise; $\triangle \mathrm{IC}$ : change in inspiratory capacity; MSIP: maximal sustainable inspiratory pressure; \% pred: percentage of the predicted value. *: $p \leqslant 0.05$ versus non-NFA; **: $\mathrm{p}<0.01$ versus baseline in same group. cycloergometry was repeated on two additional days, the variation coefficient among the three measurements was $1-6 \%$ at baseline and $5-12 \%$ at peak exercise.

Receiver operating curves showed that the dyspnoea score at peak exercise was the best marker for identifying NFA patients, a score of $\leqslant 6$ being the best cut-off point, with a sensitivity of $100 \%$ and a specificity of $63 \%$. The latter property decreased dramatically for similar levels of sensitivity when dyspnoea scores at rest or at the end point of either the 6MWD or ITL tests were used (table 3 ).

\section{Pulmonary and muscle function}

The mean values for pulmonary and both respiratory and peripheral muscle function are shown in table 1. Both groups exhibited moderate airway obstruction, with positive response to bronchodilators, moderate air trapping and mild dynamic hyperinflation (as measured by IC). In contrast, $\mathrm{Pa}, \mathrm{O}_{2}, \mathrm{~Pa}_{2} \mathrm{CO}_{2}$ and $D \mathrm{~L}, \mathrm{CO}$ were within the normal range in most subjects from both groups. No differences were found with respect to breathing pattern between NFA and non-NFA patients, at either rest, peak cycle exercise or the end point of the ITL test (fig. 4). The IC at the end of cycle exercise was significantly lower than at rest in NFA patients, showing a similar trend in the non-NFA group ( $\mathrm{p}=0.07)$ (table 2). Furthermore, the drop in IC during exercise was proportionally higher in the NFA

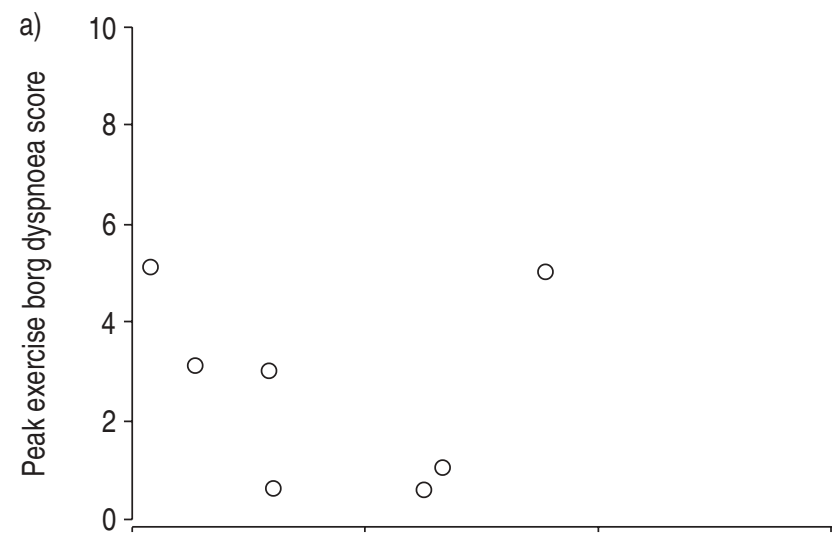

b)
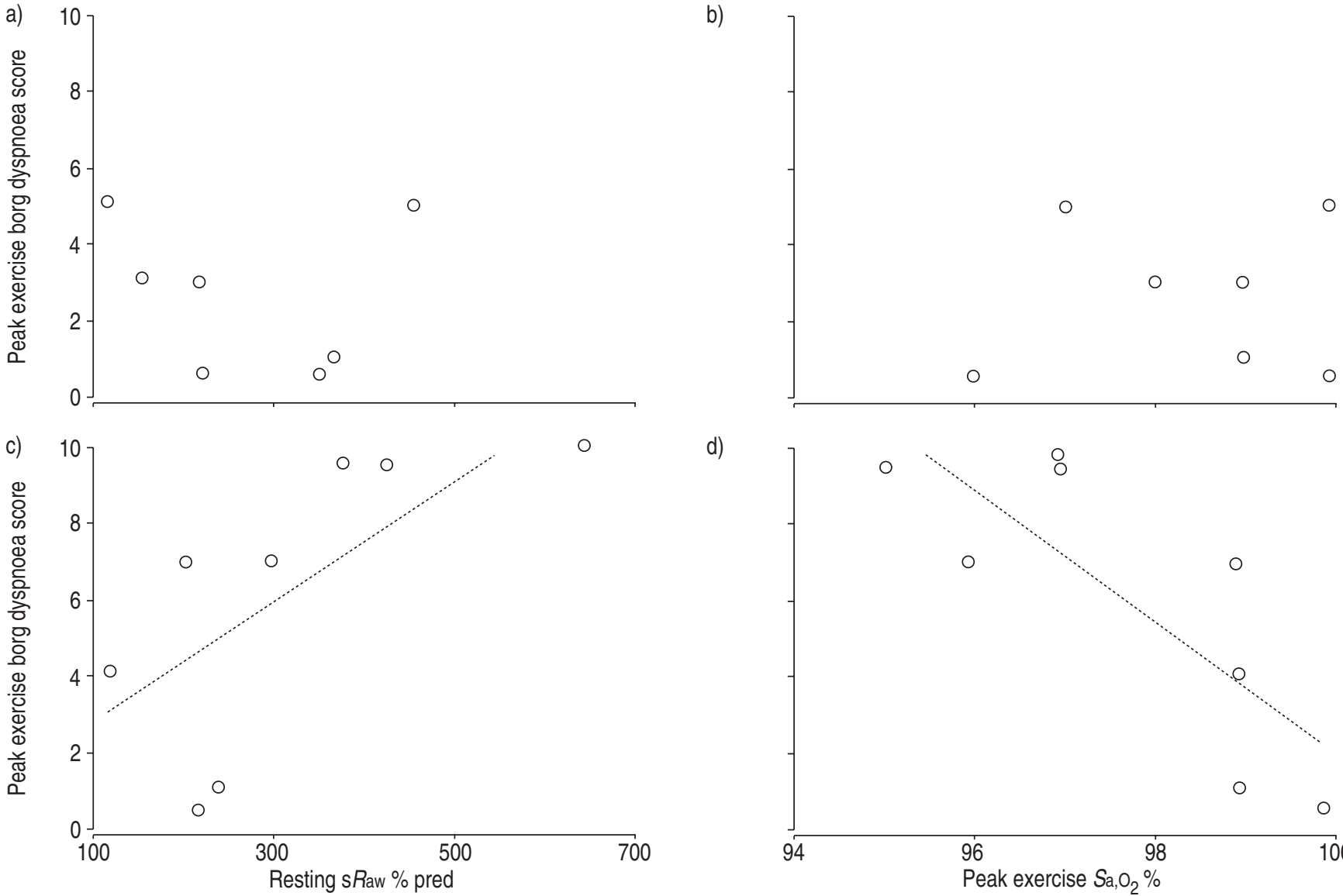

d)

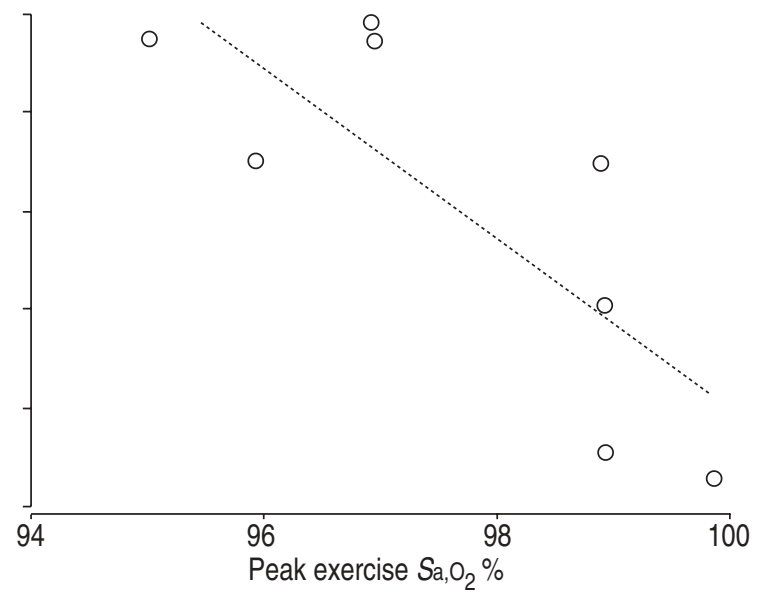

Fig. 3. - Relationships between Borg dyspnoea score at peak cycle exercise and a, c) resting specific airway resistance (sRaw), and b, d) peak exercise arterial oxygen saturation $\left(\mathrm{S}_{\mathrm{a}, \mathrm{O}_{2}}\right)$ in $\left.\mathrm{a}, \mathrm{b}\right)$ near-fatal asthma (NFA) and $\mathrm{c}$, d) non-NFA $(\mathrm{r}=0.77$ and -0.76 , respectively, both $\mathrm{p}<0.05$ ) groups. \% pred: per cent predicted. 
Table 3. - Best cut-offs for Borg dyspnoea scores at rest and at the end point of various forms of exercise as markers of the near-fatal asthma condition ${ }^{\#}$

\begin{tabular}{lcc}
\hline Cut-off & Sensitivity $\%$ & Specificity \% \\
\hline Rest & & \\
$\quad \leqslant 1$ & 100 & 38 \\
$\quad 0$ & 86 & 75 \\
Peak exercise (cycloergometer) & 100 & 63 \\
$\quad \leqslant 6$ & 72 & 75 \\
$\quad \leqslant 3$ & 100 & \\
6 -min walking distance end point & 86 & 25 \\
$\quad \leqslant 4$ & & 50 \\
$\quad \leqslant 3$ & 100 & 38 \\
Inspiratory threshold loading end point & 86 & 63 \\
$\quad \leqslant 5$ & & \\
$\quad \leqslant 1$ & & \\
\hline
\end{tabular}

\#: from receiver operating curves.

group, indicating greater enhancement of dynamic pulmonary hyperinflation than in the control group. The IC at the end of both the 6MWD and ITL tests showed a tendency to decrease compared to resting values in both groups of patients. MIP was mildly reduced in the NFA group, whereas this parameter was preserved in control patients (table 1). Conversely, peripheral muscle strength was reduced in both groups (table 1). There were no significant differences in either respiratory or muscle function variables between NFA and non-NFA patients.

\section{Exercise tolerance}

Exercise tolerance, evaluated through either the 6MWD, incremental cycloergometry or ITL test was, on average, preserved or mildly reduced, and did not differ significantly between NFA and non-NFA patients (table 2). $\mathrm{Sa}, \mathrm{O}_{2}$ at peak cycle exercise were similar to those at rest and did not differ between NFA and non-NFA patients ( $98 \pm 2 \%$ in both groups). In addition, with regard to the ratio between minute ventilation at peak exercise and maximal voluntary ventilation $(0.8 \pm 0.4)$, there were no significant differences between the two groups of asthmatic patients. Maximal workload and oxygen uptake correlated significantly with resting IC ( $\mathrm{r}=0.59$ and $\mathrm{r}=0.64$, both $\mathrm{p}<0.05$ ) in non-NFA patients, but not in the NFA group. Similar correlation coefficients were observed with peak exercise IC. The main reason for interrupting the cycloergometric test was leg discomfort in six of the seven $(86 \%)$ patients $(\mathrm{p}<0.001)$ in the NFA group on the one hand, and dyspnoea was, on the other, the main $(75 \%)$ cause in the non-NFA group $(\mathrm{p}<0.001)$. However, the ITL test was interrupted because of respiratory discomfort in all patients.

\section{Discussion}

The main finding of the present study is that perception of dyspnoea is blunted in NFA patients at both rest and the end point of various exercises. In addition, the mechanisms involved in the exercise limitation observed in NFA patients are different from those found in non-NFA subjects: the former stop exercising mainly because of leg discomfort, whereas the latter stop predominantly because of dyspnoea. Finally, Borg dyspnoea score at peak exercise appears to be the best NFA indicator.

KIKUCHI et al. [10] have shown that subjects with a previous history of NFA have a diminished perception of dyspnoea when breathing against inspiratory resistive loads
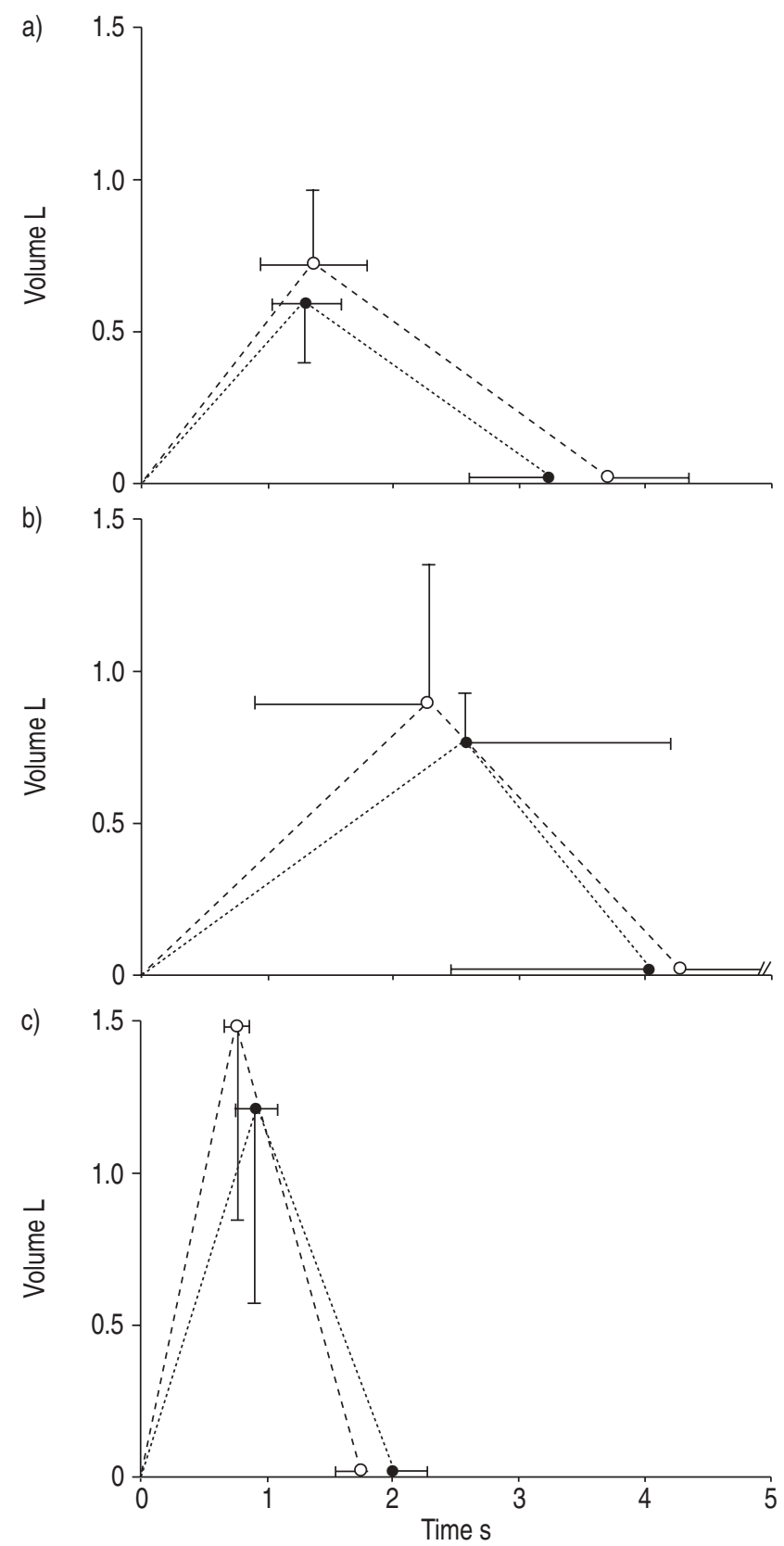

Fig. 4.-Representation of breathing patterns a) at rest, and at the end points of b) inspiratory threshold loading and c) incremental cycloergometry in near-fatal asthma (NFA; $; \cdots \cdots .$.$) and non-NFA$ $(\bigcirc$; ----) patients. Data are presented as mean \pm SD.

and exhibit a reduced response to experimental hypoxia and hypercapnia. These authors concluded that reduced chemosensitivity and blunted perception of dyspnoea may predispose patients to fatal asthma attacks. In addition, CATELLIER et al. [24] reported that those asthmatic patients who exhibit reduced perception of symptoms also show impaired ability to detect bronchoconstriction and related changes in lung volumes. In line with this, it was shown, in another study, that low baseline FEV1 and high bronchial responsiveness are associated with low perception of dyspnoea during histamineinduced bronchoconstriction [9]. Taken together, these three studies strongly suggest that NFA patients have a dysfunction in the proprioceptive pathways involved in the ventilatory system's response to changes in respiratory gas levels and/or mechanics. 
In the present study, it was found that, even at rest, the perception of dyspnoea is decreased in NFA patients compared to non-NFA patients. This discrepancy with the results of KIKUCHI et al. [10] may be due to the fact that the present NFA population exhibited chronic airway obstruction, whereas their patients showed normal FEV1. The present study also shows that, in NFA patients, the perception of dyspnoea is decreased during inspiratory loading, as previously demonstrated by KIKUCHI et al. [10]. However, ITL rather than resistive breathing was employed in the present study. This better mimics the real situation in an asthma attack, where intrinsic positive end-expiratory pressure (PEEPi) due to pulmonary hyperinflation is the most important load and acts through a threshold mechanism. Similarly, blunted perception of dyspnoea occurred in the present NFA patients at the end point of various levels of effort, which included peak exercise (cycloergometry) as well as the 6MWD test, which can be considered closer to daily life activities. The finding that $\mathrm{Sa}, \mathrm{O}_{2}$ at peak exercise correlated with dyspnoea in the non-NFA patients, but not in the NFA group, again suggests that the latter showed reduced oxygen chemosensitivity [10], even in the absence of dramatic falls in $P \mathrm{a}, \mathrm{O}_{2}$. It should be taken into consideration, however, that hypoxia per se may have a "dyspnogenic" effect over and above its reflex stimulation of ventilation [25]. Similarly, dyspnoea at peak exercise was found to be directly related to the level of resting airway resistance in the present non-NFA group, being independent in NFA patients. This also supports the notion of blunted perception of respiratory resistance in the latter.

In agreement with previous authors, the present authors consider that the blunted perception of dyspnoea occurring in the current patients was probably the result of altered signalling and/or processing of information from pathways involved in the control of breathing. Alternative mechanisms, such as a stoical attitude to discomfort, temporal adaptation or the effects of drugs, are unlikely in the present study given the fact that the patients were carefully selected, did not manifest any special psychological profile, as shown by the multiple tests contained in the ENFUMOSA study, and had not taken any medication known to influence perception of dyspnoea.

A relevant finding in the present study is the identification of Borg dyspnoea score at peak exercise as a good indicator of the NFA condition. In this regard, a cut-off of $\leqslant 6$ identifies all NFA patients with an acceptable level of specificity, a result which has recently been confirmed in an additional set of patients (data not shown). Since the specificity decreases dramatically when dyspnoea at rest is used for the same purpose, the present authors propose that functional assessment of patients with severe asthma should include incremental cycloergometry. This clinical implication, however, should not be taken lightly due to its economic repercussions.

The present study also shows that overall exercise tolerance is moderately reduced in patients with severe asthma, with or without NFA. This is in keeping with previous studies performed in asthmatic patients of differing ages [26-30]. In non-NFA patients, however, the main reason for stopping the exercise was dyspnoea, and maximal exercise capacity was closely related to resting pulmonary hyperinflation. Conversely, leg symptoms were predominant in NFA patients, in whom no relationship was found between exercise capacity and lung volumes.

Pulmonary hyperinflation in asthma can be caused by various mechanisms, including loss of elastic recoil, tonic inspiratory activity in ribcage muscles, gas trapping, bronchoconstriction and expiratory airflow limitation [31-33]. The latter leads to dynamic hyperinflation [34], which, in turn, results in impairment of respiratory muscle function $[35,36]$, as well as development of PEEPi [37]. Pulmonary hyperinflation can even increase in various situations, such as exacerbations or exercise in patients with chronic lung diseases [28]. This is due to the fact that flow-limited patients increase their minute ventilation mainly by increasing their respiratory frequency since only minor changes can be achieved in tidal volume due to their already reduced inspiratory reserve. This results in the displacement of the flow/volume curve and increase in lung volumes, which also contribute to exercise limitation. The enhancement of pulmonary hyperinflation exhibited by the present severe asthmatic patients during exercise strongly suggests the presence of expiratory flow limitation [28, 38]. This differs from previous findings in subjects with stable mild-to-moderate asthma, in whom expiratory flow limitation and pulmonary hyperinflation rarely occur [39]. However, the exercise-induced increase in lung volumes does not appear to be a crucial contributor to exercise limitation in the present patients, provided that the correlation coefficients were similar to those obtained with resting $\mathrm{IC}$.

One potential limitation of the present study is the existence of a relative delay in some of the measurements following exercise, which might have affected some of the results. However, this does not seem very likely, at least for IC, since it was determined at the precise moment at which the patients stopped exercising. Indeed, this approach was chosen rather than measuring IC during task failure, as it is difficult to perform a valid manoeuvre under such conditions (intraindividual variation of $27 \%$ in the authors' laboratory).

As far as the present authors are aware, this is the first time that dyspnoea and its relationships with exercise capacity and limiting factors have been fully evaluated in patients with severe asthma, with or without a history of near-fatal asthma. The findings of the present study may have relevant clinical implications. Indeed, the authors propose that early detection of near-fatal asthma candidates and assessment of their asthma status should be based on both subjective (dyspnoea scales under different conditions) and objective (lung function) measurements. Existence of a dichotomy between these two types of evaluation would suggest a risk of near-fatal asthma. In addition, dyspnoea at peak exercise could also be used as an indicator of near-fatal asthma.

Acknowledgements. The authors are grateful to N. Soler and A. Roig for technical assistance, and to R. Marshall for editing aid.

\section{References}

1. Mitchell I, Tough SC, Semple LK, Green FH, Hessel PA. Near-fatal asthma: a population-based study of risk factors. Chest 2002; 121: 1407-1413.

2. Bucknall CE, Slack R, Godley CC, McKay TW, Wright SC. Scottish confidential inquiry into asthma deaths (SCIAD), 1994-6. Thorax 1999; 54: 978-984.

3. Burr ML, Davies BH, Hoare A, Jones A, Williamson IJ, Holgate SK. A confidential inquiry into asthma in Wales. Thorax 1999; 54: 985-989.

4. Weiss KB, Sullivan SD. The economic costs of asthma: a review and conceptual model. Pharmacoeconomics 1993; 4 $14-30$.

5. Beasley R, Pearce N, Crane J. Use of near-fatal asthma for investigating asthma deaths. Thorax 1993; 48: 1093-1094.

6. Turner MO, Noertjojo K, Vedal S, Bai T, Crump S, Fitzgerald JM. Risk factors for near-fatal asthma: a casecontrol study in hospitalized patients with asthma. Am J Respir Crit Care Med 1998; 157: 1804-1809. 
7. Campbell DA, McLennan G, Coates JR, et al. A comparison of asthma deaths and near-fatal asthma attacks in South Australia. Eur Respir J 1994; 7: 490-497.

8. Magadle R, Berar-Yanay $\mathrm{N}$, Weiner $\mathrm{P}$. The risk of hospitalization and near-fatal asthma in relation to the perception of dyspnea. Chest 2002; 121: 329-333.

9. Bijl-Hofland ID, Cloosterman SGM, Folgering HT, Akkermans RP, van Schayk CP. Relation of the perception of airway obstruction to the severity of asthma. Thorax 1999; 54: $15-19$.

10. Kikuchi Y, Okabe S, Tamura G, et al. Chemosensitivity and perception of dyspnea in patients with a history of near-fatal asthma. New Engl J Med 1994; 330: 1329-1334.

11. National Heart, Lung, and Blood Institute, National Institutes of Health. International consensus report on diagnosis and treatment of asthma. Eur Respir J 1992; 5: 601-641.

12. American Thoracic Society. Standardization of spirometry: 1994 update. Am J Respir Crit Care Med 1995; 152: 11071136.

13. Roca J, Sanchís J, Agustí-Vidal A, et al. Spirometric reference values from a Mediterranean population. Bull Eur Physiopathol Respir 1986; 22: 217-224.

14. Roca J, Burgos F, Barberà JA, et al. Prediction equations for plethysmographic lung volumes. Respir Med 1998; 92: 454-460.

15. Roca J, Rodríguez-Roisin R, Cobo E, Burgos F, Pérez J, Clausen JL. Single-breath carbon monoxide diffusing capacity prediction equations from a Mediterranean population. Am Rev Respir Dis 1990; 141: 1026-1032.

16. Morales P, Sanchis J, Cordero PJ, Diez JL. Maximum static respiratory pressures in adults. The reference values for a Mediterranean Caucasian population. Arch Bronconeumol 1997; 33: 213-219.

17. Mathiowetz V, Dove M, Kashman N, Rogers S. Grip and pinch strength: normative data for adults. Arch Phys Med Rehabil 1985; 66: 69-72.

18. Borg GAV. Psychophysical bases of perceived exertion. Med Sci Sports Exerc 1982; 14: 377-381.

19. Butland RJA, Pang J, Gross ER, Woodcock AA, Geddes DM. Two-, six-, and twelve-minute walking test in respiratory disease. BMJ 1982; 284: 1007-1008.

20. Enright PL, Sherrill DL. Reference equations for the sixminute walk in healthy adults. Am J Respir Crit Care Med 1998; 158: 1384-1387.

21. Jones NL, Makrides L, Hitchcock J, et al. Normal standards for an incremental progressive cycle ergometer test. Am Rev Respir Dis 1985; 131: 700-708.

22. Martyn JB, Moreno RH, Paré PD, Pardy RL. Measurement of inspiratory muscle performance with incremental threshold loading. Am Rev Respir Dis 1987; 135: 919-923.

23. Fiz JA, Romero P, Gomez R, et al. Indices of respiratory muscle endurance in healthy subjects. Respiration 1998; 65: 21-27.

24. Catellier P, Turcotte H, Deschesnes F, Boulet LP. Changes in lung volumes and poor perception of bronchoconstrictioninduced respiratory symptoms. Ann Allergy Asthma Immunol 1998; 81: 315-321.

25. Adams L. Reflex respiratory stimulation and respiratory sensation. In: Adams L, Guz A, eds. Respiratory Sensation. New York, NY, Marcel Dekker, Inc., 1996; pp. 201-211.

26. Clark CJ, Cochrane LM. Assessment of work performance in asthma for determination of cardiorespiratory fitness and training capacity. Thorax 1998; 43: 745-749.

27. Satta A. Exercise training in asthma. J Sports Med Phys Fitness 2000; 40: 277-283.

28. Murariu C, Ghezzo H, Milic-Emili J, Gautier H. Exercise limitation in obstructive lung disease. Chest 1998; 114: 965968.

29. Counil FP, Varray A, Karila C, Hayot M, Voisin M, Prefaut C. Wingate test performance in children with asthma: aerobic or anaerobic limitation? Med Sci Sports Exerc 1997; 29: 430-435.

30. Suman OE, Babcock MA, Pegelow DF, Jarjour NN, Reddan WG. Airway obstruction during exercise in asthma. Am J Respir Crit Care Med 1995; 152: 24-31.

31. Gold WM, Kaufman MS, Nadel JA. Elastic recoil of the lungs in chronic asthmatic patients before and after therapy. J Appl Physiol 1967; 23: 433-438.

32. Peress L, Sybrecht G, Macklem PT. The mechanism of increase in total lung capacity during acute asthma. Am $J$ Med 1976; 61: 165-169.

33. Freedman S, Tattersfield AE, Pride NB. Changes in lung mechanics during asthma induced by exercise. J Appl Physiol 1975; 38: 974-982.

34. O'Donnell DE, Webb KA. Exertional breathlessness in patients with chronic airflow limitation: role of lung hyperinflation. Am Rev Respir Dis 1993; 148: 1351-1357.

35. Macklem PT. Hyperinflation. Am Rev Respir Dis 1984; 129 : $1-2$.

36. Decramer M. Hyperinflation and respiratory muscle interaction. Eur Respir J 1997; 10: 934-941.

37. Rossi A, Polese G, Brandi G, Conti G. Intrinsic positive endexpiratory pressure (PEEPi). Intensive Care Med 1995; 21: $522-536$.

38. Diaz O, Villafranca C, Ghezzo $\mathrm{H}$, et al. Role of inspiratory capacity on exercise tolerance in COPD patients with and without tidal expiratory flow limitation at rest. Eur Respir $J$ 2000; 16: 269-275.

39. Boczkowski J, Murciano D, Pichot MH, Ferreti A, Pariente R, Milic-Emili J. Expiratory flow limitation in stable asthmatic patients during resting breathing. Am J Respir Crit Care Med 1997; 156: 752-757. 